\title{
firIISGUC.ORG
}

"IST, GÜC̣" ENDÜSTRi ilLișKiLERi VE INSAN KAYNAKLARI DERGisi

"IS, GUC" INDUSTRIAL RELATIONS AND HUMAN RESOURCES JOURNAL

\section{İşletme Stratejisi ve Performans Yönetimi İlişkisi: Strateji-Yapı Perspektifi}

\author{
Business Strategy and Performance Management: \\ Strategy Structure Perspective
}

\author{
Mert AKTAŞ \\ Yrd. Doç. Dr./
}

Ocak/January 2012, Cilt/Vol: 14, Say1/Num:1, Page: 91-102

ISSN: 1303-2860, DOI: 10.4026/1303-2860.2012.196.x

Makalenin on-line kopyasına erişmek için:

http://www.isguc.org/? $\mathrm{p}=$ article\&id=475\&vol=14\&num=1\&year=2012

To reach the on-line copy of article:

http://www.isguc.org/?p=article\&id=475\&vol=14\&num=1\&year=2012

Makale İçin İletişim/Correspondence to: 
(C) 2000- 2012

“İşGüç" Endüstri İlişkileri ve İnsan Kaynakları Dergisi

"İşGüç" Industrial Relations and Human Resources Journal

\author{
Ocak/January 2012, Cilt/Vol: 14, Sayı/Num: 1 \\ ISSN: 1303-2860, DOI: 10.4026/1303-2860.2012.196.x
}

\section{Editör/Editor-in-Chief \\ Aşkın Keser (Uludă̆ University)}

Editör Yardimcılari/Co-Editors

K.Ahmet Sevimli (Uludağ University)

Gözde Yilmaz (Marmara University)

Uygulama/Design

Yusuf Budak (Kocaeli Universtiy)

\author{
Yayın Kurulu / Editorial Board \\ Dr. Erdem Cam (ÇASGEM) \\ Dr. Zerrin Furat (Uludă̆ University) \\ Doç. Dr. Aşkın Keser (Uludağ University) \\ Prof. Dr. Ahmet Selamoğlu (Kocaeli University) \\ Yrd. Doç. Dr. Ahmet Sevimli (Uludăg University) \\ Doç. Dr. Abdulkadir Şenkal (Kocaeli University) \\ Doç. Dr. Gözde Yilmaz (Marmara University) \\ Dr. Memet Zencirkıran (Uludă̆ University)
}

Uluslararası Danışma Kurulu / International Advisory Board Prof. Dr. Ronald Burke (York University - CA)

Assoc. Prof. Dr. Glenn Dawes (James Cook University - AU)

Prof. Dr. Jan Dul (Erasmus University - NL)

Prof. Dr. Alev Efendioğlu (University of San Francisco - USA)

Prof. Dr. Adrian Furnham (University College London - UK)

Prof. Dr. Alan Geare (University of Otago - NZ)

Prof. Dr. Ricky Griffin (TAMU-Texas AEM University - USA)

Assoc. Prof. Dr. Diana Lipinskiene (Kaunos University - LT)

Prof. Dr. George Manning (Northern Kentucky University - USA)

Prof. Dr. William L. Murray (University of San Francisco - USA)

Prof. Dr. Mustafa Özbilgin (Brunel University - UK)

Assoc. Prof. Dr. Owen Stanley (James Cook University - AU)

Prof. Dr. Işık Urla Zeytinoğlu (McMaster University - CA)

\section{Ulusal Danışma Kurulu / National Advisory Board}

Prof. Dr. Yusuf Alper (Uludă̆ University)

Prof. Dr. Veysel Bozkurt (İstanbul University)

Prof. Dr. Toker Dereli (Işık University)

Prof. Dr. Nihat Erdoğmuş (Şehir University)

Doç. Dr. Mustafa Kurt (Yalova University)

Prof. Dr. Ahmet Makal (Ankara University)

Prof. Dr. Süleyman Özdemir (İstanbul University)

Prof. Dr. Ahmet Selamoğlu (Kocaeli University)

Prof. Dr. Nadir Sŭ̆ur (Anadolu University)

Prof. Dr. Nursel Telman (Maltepe University)

Prof. Dr. Cavide Uyargil (İstanbul University)

Prof. Dr. Engin Yildirum (Constitutional Court of Turkey)

Doç. Dr. Arzu Wasti (Sabancı University)

Dergide yayınlanan yazılardaki görüşler ve bu konudaki sorumluluk yazarlarına aittir.

Yayınlanan eserlerde yer alan tüm içerik kaynak gösterilmeden kullanılamaz.

All the opinions written in articles are under responsibilities of the outhors.

The published contents in the articles cannot be used without being cited. 


\title{
İşletme Stratejisi ve Performans Yönetimi İlişkisi: Strateji-Yapı Perspektifi
}

\author{
Business Strategy and Performance Management: \\ Strategy Structure Perspective
}

\author{
Mert AKTAŞ
}

\begin{abstract}
Özet
Bu araştırmada daha önce ele alınmayan performans yönetimi ile işletme stratejisinin ilişkisi ele alını incelenmiştir. Bu ilişki ele alınırken, tartışma Porter'ın(1980) düşük maliyet liderliği ve farklılaşma olmak üzere iki temel işletme seviyesindeki jenerik stratejiler yönü ile ele alınmıştır. Bu stratejilerin performans yönetiminin üç temel aşaması olan hedef kurma, değerlendirme ve ödüllendirme üzerindeki etkisi incelenmiştir. Araştırma sonucu olarak, maliyet liderliği stratejisinde örgütsel dizaynın parçası olarak sert performans yönetimi uygulamalarının öne çıkacağı, öbür tarafta ise farklılaşma stratejisi izleyen firmalarda ise mülayim performans yönetimi uygulamalarmın kullanılacağı tartışılmıştır.
\end{abstract}

Anahtar Sözcükler: İşletme stratejisi, performans yönetimi

\begin{abstract}
In this paper the relationship between organizational strategy and performance management is investigted. In this research Porter's (1980) cost leadership and differentation is taken as two main business level strategies. And its impact on goal setting, performance appraisal and reward as three main steps of performance management is investigated. As a result of theoretical framework it is stated that cost leadership strategy will bring the use of hard performance management practices and differantion strategy will require soft performance management practices.
\end{abstract}

Keywords: Business strategy, performance management 


\section{Giriş}

Son yillarda artan rekabet ve küreselleşme insan kaynaklarının etkin ve verimli kullanılmasını gerekli kıldığı bir çokları tarafından kabul edilmiştir (Boxall ve Steenveld, 1999; Schuler ve Jackson, 1987; Guest ve Conway; 1998 ... ). Ve son yıllarda insan kaynaklarının stratejik rolü önemli hale gelmiştir (SanzValle, 1999). Buna ilişkin olarak stratejik IKKY alanı önemli bir tarışma konusu olmuş ve çeşitli perspektifler ortaya çıkmıştır.

Stratejik insan kaynakları yazınını üç temel paradigma domine etmektedir. Bunlar kaynağını insan ilişkileri kuramından alan Japon işyeri uygulamalarının popülaritesinin artmasi ile yaygin olarak yer bulan evrenselci görüş (Guest, 1998; Capelli ve Neumark, 2001) , kaynağını kaynak odaklı firma yaklaşımından alan stratejik İKY yaklaşımı (Prahalad ve Hamel, 1990; Barney, 1991; Boxall ve Steenveld, 1999) ve kaynağını koşulbağımlılık kuramından alan stratejik İKY (Miles ve Snow, 1984; Schuler ve Jackson, 1987) yaklaşımlarıdır.

Stratejik İnsan Kaynakları Yönetiminin güncel yazınının önemli bir kısmı evrensel kaynağını insan ilişkileri yaklaşımından alan katılımc1 (Guest ve Conway, 1998;2000;2001) ve yenilikçi (Capelli ve Neumark, 2001) bir demet insan kaynakları yönetimi uygulamalarının örgütsel performansı arttırdığ 1 tartışılmıştır. Bu tezin ana fikri bir takım yüksek kaliteli ve içsel olarak tutarlı insan kaynakları yönetimi uygulamalarının örgütsel performansı arttırdığıdır (Huselid ve diğerleri, 1997:173). Burada yüksek kaliteli (Hüselid ve diğerleri, 1997) veya yenilikçi (Capelli ve Neumark; 2001) İKY uygulamalarının ana fikri çalışan katılımının sağlanmasıdır. Bu uygulamalar toplam kalite yönetimi uygulamaları, görüşmeler, takım çalışması eğitimi, yetkinli için ödeme, kar paylaşımı (Capelli ve Neumark, 2001) olarak tanımlanmıştır.

Kaynak odaklı firma görüşünden doğan, stratejik insan kaynakları yönetimi yazını ise firmanin taklit edilmesi pahalı olan (Conner, 1991) veya başka bir ifade ile hatasız olarak taklit edilemez (Barney, 1992) karakteristikleri bir takım firmalara yüksek performans ve rekabetçi avantaj sağladığını tartışmaktadır. Bu görüşe göre, firmanın, rekabetçi olarak değerli yetkinlikleri olan insanları istihdam etmesi; bu insan sermayesi avantaj1 olarak adlandırılmaktadır; ve bölümler arası işbirliği veya genel müdür gelişimi gibi firma içinde evrimleşmiş ve taklit edilmesi zor insan süreci avantajı olarak adlandırılan bu iki temel avantajın birleşimi firmanın insan kaynağ 1 avantajını oluşturur (Boxall ve Steenveld, 1999). Uyum perspektifinin aksine belirli stratejilerde olan firmalarda aynı olması gereken İKY uygulamalarının değil; firmanın tarihsel sürecinde evrimleşmiş bir takım İKY uygulamalarının rekabetçi avantaj yaratacağ1 görüşünü savunur.

Öbür tarafta ise, koşulbağımlılık perspektifinden çıkan stratejik iky perspektifi ise insan kaynakları yönetimi uygulamalarının örgütlerin içsel ve dişsal faktörlerine göre belirleneceği tartışılmıştır (Jackson ve Schuler, 1995; Delery ve Dotty, 1996). İçsel faktörler teknoloji, yapı büyüklük, örgütün yaşam döngüsündeki yeri ve örgütün stratejisi olarak ele alınırken dışsal faktörler olarak ise yapisal sosyal ve politik çevre, sendikalar, işgücü pazarı koşulları, sektör özellikleri ve ulusal kültür ele alınmıştır. (Delery ve Dotty, 1996). Schuler ve Jackson (1987) tartışmasında insan kaynakları yönetimi uygulamalarının örgütün stratejik yönetim süreçleri ile uyumlu olması gerektiğini tartışmışlardır. $\mathrm{Bu}$ uyum üç kavramsal değişkende uyum olmalıdır. İnsan kaynakları uygulamaları (Schuler ve Jackson, 1987; Miles ve Snow, 1984; Wright ve Snell, 1991), çalışan yetkinlikleri (Gerstein ve Reisman, 1983; Hambrick ve Mason, 1984;Kerr, 1982; Olian ve Rynes; 1984) ve çalışan davranışlarının (Schuler ve Jackson, 1987) örgüt stratejisi ile uyumlu olmalıdir.

İnsan kaynakları yönetimi alanında şimdiye kadar ki çalışmalar, genel olarak insan kaynakları ve strateji ilişkisini bir çok araştırmaya konu olmuştur (Devanna ve diğerleri, 1984; Miles ve Snow, 1984; Schuler ve 
Jackson, 1987) .Bu araştırmalar ve kavramlar üzerine inşaa edilen başka bir takım araştırmalar, insan kaynakları yönetimi ile strateji ilişkisini; işe alım (Olian ve Rynes, 1994; Raghuram, 1994; Raghuram ve Arvey, 1994), eğitim ve gelişim (Raghuram, 1994; Raghuram ve Arvey, 1994) ödüllendirme sistemleri (Balkin ve Gomez, 1990; Armstrong ve Murlis, 1998) gibi insan kaynakları yönetiminin alt başlıkları ve uygulama alanları yönü ile de kurmuşlardır.

Yukarıda sıralandı $\breve{g}_{1}$ gibi işletme stratejisi ve insan kaynakları alt başlıkları ilişkisi bir çok alt alan ile kurulmuş olmakla birlikte, performans değerlendirmesi daha kapsamlı bir ifade ile performans yönetimi ile ilişkisi kurulmamıştır. Bu çalışmada İşletme stratejisi ile performans yönetimi uygulamaları arasındaki ilişki ele alınacaktır. İşletme stratejisi olarak Porter'in (1980) işletme seviyesindeki jenerik strateji tipolojileri ele alınmıştır. Performans yönetiminde ise Legge(1995) sert ve mülayim insan kaynakları yaklaşımından çıkan sert ve yumuşak performans yönetimi ele alınmıştır. Bu araştırmada insan kaynakları yönetiminin bir alt başlığ1 ve uygulaması olan performans yönetimi uygulamalarının örgütlerde strateji yapı çerçevesi içerisinde değerlendirilecek ele alınacak ve farklı örgüt stratejileri için farklı performans yönetimi uygulamaları önerilecektir. Stratejik yönetim perspektifinden baktığımız zaman, eğer strateji bir programlama ve hedefleri ortaya koyma süreci ise performans yönetiminin de örgütsel hedefleri misyonu alt birim hedefleri haline getirmekte bir aracı olarak (Harrison, 1993) önemli bir araştırma konusudur.

\section{KURAMSAL ÇERÇEVE}

\section{Strateji Yapı Çerçevesi ve Jenerik Strateji Ti- polojileri}

Örgütler stratejik programlama ile örgütsel hedefi aksiyon aşamalarına ve alt hedeflere dönüştürürler (Mintzberg, 1984). Stratejilerin gerektirdikleri, koordinasyon, teknik ve kontrol görevleri sebebi ile örgüt- sel yapılara çok önemli etkileri vardır (Miller, 1988). Bu perspektif örgütsel stratejinin uygulanabilmesi ve örgütsel hedeflere ulaş1labilmesi için örgütün yapısal bileşenlerinin strateji ile uyumlu olması gerektiğini tartışmiştır (Miller, 1986: 234). Uyum(fit) Nadler ve Tushman (1980:40) tarafından "bir bileşenin taleplerinin, hedeflerinin, ve/veya yap1sinın hangi dereceye kadar bir başka bileşenin talepleri hedefleri ve/veya yapısı ile tutarlı olduğu" şeklinde tanımlanmıştır.

$\mathrm{Bu}$ tartışma işletme politikasında çok uzun süredir kabul edilmiş iki temel varsayıma dayanmaktadır (Bart, 1986). Bunlardan birisi, işletme stratejisi ile örgütsel yapı arasında bir ilişki olduğu; ikincisi ise işletme stratejilerini gerçekleştirebilmek için bir takım yapısal ayarlamalara ihtiyaç duyulduğu varsayımlarıdır (Bart, 1986). Bu bakış açısına göre uygun bir şekilde dizayn edilmiş iş tanımlamaları, enformasyon sistemleri, yönetici seçim sistemleri ve ödüllendirme sistemleri gibi yapısal bileşenler strateji ile uyumu stratejinin uygulanabilmesi ve ulaş1lalabilmesi açısından zorunludur (Bart, 1986; Ginsberg ve Venkatraman, 1985; Mintzberg, 1984; Miller, 1986). Bu yaklaşımin insan kaynakları yönetimi uygulamalarına etkisi ise, çalışan davranışlarının örgüt stratejisi için önemli olduğu ve bu stratejiyi destekleyecek çalışan davranışlarını geliştirmek için de bir takım çalışan davranışını etkileyecek bir takım yönetim aktivitelerinin izlenmesi gerektiği yatmaktadır (Wright ve Snell, 1998).

$\mathrm{Bu}$ yapısal bileşenler iş tanımları, enformasyon sistemleri, yönetici seçim sistemleri, ödül sistemleri vb olarak tartışılmıştır (Bart, 1986). Miller'ın (1986:235) tartıştığ 1 gibi yenilikçi bir strateji ile mekanik bir yapı nasıl mümkün olabilecektir. Yenilikçi bir yapı karar vermenin gayri merkezi olmasını gerektir ve bu da ancak organik yapilarda mümkündür (Miller,1986: 236).

Stratejik yönetim yazınında dört tip temel örgütsel strateji konfigürasyonundan veya tipolojilerinden bahsedilmiştir (Miller, 1986: 237). Bu strateji tipolojileri farklılaşma, maliyet liderliği, odak(focus) ve varlık özgüllüğü 
(asset parsimony)(Miller, 1986; Miller; 1988). Odak kurumsal (corporate) seviyede ele al1nabilirken maliyet liderliği ve fakrlılaşma stratejileri işletme seviyesindeki stratejilerdir (Miller, 1986).

Maliyet liderliği stratejisini benimsemiş firmalar ürettikleri mal ve hizmetleri rekabet ettikleri firmalardan daha ucuz bir biçimde üretmeye çalışırlar (Miller, 1986;1988;1996). Bu sebeple verimli ölçek fırsatına önem verirler ve bu amaçla üretimde maliyeti düşürmeye, serviş satış reklam ve Ar-ge maliyetlerini minimize etmeye çalışırlar (Miller, 1988). Standartlaştırılmış yüksek kapasitede ürünü en düşük fiyata sağlamaya çalışırlar. Bu sebeple çok az yenilik yapmaya çabalarlar çünkü yenilik yapmak verimliliği tahrip eder (Miller, 1986). Bu strateji tipolojisinin temel özelliği, etkinliği sağlamak, deneyim eğrisi politikalarını uygulamak, ana merkez kontrolü sağlamak ve bu şekilde maliyetleri kontrol altında tutmaktır (Galbraith ve Schendel, 1983). Kar ve bütçe kontrolü üzerine vurgu yaparlar (Miller, 1988). Bu stratejiyi izleyen örgütler, operasyonel verimliliği sağlamak, yüksek envanter seviyeleri bulundurmak, dişsal finansman kullanımını azaltmak gibi rekabetçi metodlar izledikleri vurgulanmıştır (Dess ve Davis, 1984).

Bu stratejiyi izleyen firmalarda, yapı son derece katıdır ve verimliliğe programlanmıştır (Miller, 1986). Bu stratejiyi izleyen firmalarda, kararların merkezi olduğu, ademi merkeziyetçiliğin geniş olduğu, işlerin rutin ve tekrar edici olduğ $\mathrm{u}$, bilgi akışının sadece dikey olduğu, gücün pozisyondan kaynaklandığı, özelleşmiş yönetsel yetkinliklere gerek duyulan bürokratik yapılar egemendir (Nemetz ve Fry, 1988). Bu yap1 sayesinde kontrol sağlanmaya çalışılır (Miller, 1988). Bu stratejiyi izleyen örgütlerde, işler standart olduğu için işgücünün yetkinlik kompozisyonu daha düşüktür ve bilim adamı ve mühendis gibi daha az teknokrat kullanılır (Miller, 1988).

Öbür tarafta farklılaşma stratejisi ise, özgün bir şekilde çekici olarak algılanan ürünler üretmektir (Miler, 1986). Bu örgüt stratejisinde güçlü pazarlama yeteneklerine yaratıcı ve iyi dizayn edilmiş ürünlere ve kurumsal imaj ve ürünlerin ününe ve kalitesine vurgu yapmaktadır (Miller, 1986). Miller'ın $(1986 ; 1988)$ tartışması Porter'ın (1985) tipolojisinden farklı olarak örgütlerde farklılaşma stratejisinin iki boyutta ele alınması gerektiğini vurgulamaktadır.

İlki yenilik ile farklılaşanları kapsamaktadır . Bu stratejide vurgu yaratıcılık üzerindedir ve örgütün amacı yeni teknolojiler ve ürünler üretmektir (Miller, 1986). Esas önem Ar-ge de öncülük yapmak üzerindedir ve bu şekilde rekabet avantajı sağlamaya çalışırlar (Miller, 1986). Yenilik ile farklılaşan firmalar, yeni ürün gelişimi sağlamak, daha geniş yelpazede ürünler üretmek gibi rekabetçi yöntemleri izleyerek rekabetçi avantaj1 yakalamaya çalışırlar (Dess ve Davis, 1984). Bu stratejide, yap1 esnektir ve departmanlar arası iletişime izin verir (Miller, 1986). Bu stratejide olan örgütlerde, yap1 organiktir, iletişim yataydır, kararların alınmasında merkeziyetçilik düşüktür, ademi merkeziyet dardır, bilginin kaynağını güç oluşturur, otonomi ve yerinden kontrol vardir (Nemetz ve Fry, 1988). Bu stratejiyi benimsemiş örgütlerde, bilgi yoğun işgücü, bir başka ifade ile mühendis ve bilim adamı gibi teknokratların kullanımı çok yüksektir (Miller, 1988).

Diğer farklılaşma türü ise pazarlama farklılaşmasıdır. Burada vurgu etkileyici paket, iyi servis, uygun yer ve iyi ürün kalitesi ve güvenilirliği üzerindedir (Miller, 1986;1988). Bu firmalar iyi pazarlayıcıdırlar reklamın, satışın, promosyon ve dağıtım üzerine büyük miktarlar harcarlar (Miller,1986). Bu stratejiyi izleyen firmaların kullandıkları temel rekabetçi metodlar, yüksek kalitede müşteri hizmeti, ürün kalite kontrolü, pazarlama tekniklerindeki yenilikler, reklam ve yüksek fiyat segmentinde ürün oluşturmak gibi rekabetçi metodlar izlerler (Dess ve Davis, 1984). Bu araştırmada farklılaşma stratejisi Porter'ın (1980) çalışmasındaki gibi tek boyutta ele alınacaktır. 


\section{Performans Yönetimi}

Performans yönetimi örgütün hedeflerinin bölümsel hedeflere ve bireysel hedeflere dönüştürülmesidir (Harrison, 1993). Performans yönetiminin aşamaları hedefleri belirlemek, hedeflere ne kadar ulaşıldığını tekrar etmek, eğitim ihtiyaçlarını ve ödüllendirmeyi belirlemek ve bir daha ki hedefler için gerekli düzenlemeleri yapmaktır (Mabey ve diğerleri 1998:127). Yazındaki temel tartışma bu aşamaların döngüsel bir biçimde sürekli birbirini izleyen bir süreç şeklinde işlediğidir (Harrison, 1993). Hedef belirleme, hedefleri değerlendirme ve ödüllendirme bu sürecin temel aşamalarıdır (Harrison, 1993). Performans yönetimi kuramında, bir tarafta sert performans yönetimi, performansın ölçülebilir, çıktı ve kontrol odaklı kontrole dayanan tarafında odaklanırken; öbür tarafta mülayim tarafı gelişimsel taraflarına odaklanmıştır (Bach, 2002).

Performans yönetimi sürecinin ilk aşaması hedefleri belirlemektir (Mabey ve diğerleri, 1998). Bu aşamada amaç örgüt stratejisindeki hedeflerin bireysel ve bölümsel hedeflere dönüştürülmesidir. Burada hedef belirlemede literatürde iki amaç vardır. Mülayim insan kaynakları yönetimi yaklaşımı hedef kurmanın katılımcı bir süreç olduğunu ve hedeflerin katılım ile kurulması gerektiğini vurgulanmıştır (Bach ve Sisson, 2001). Hedeflerin gelişimsel hedefler olması ve yetkinlik gelişimini motive etmesi mülayim İKY'nin temel tartışmasıdır. Öbür tarafta ise, sert IKKY hedef belirlemede hedeflerin yukarıdan aşşağı empoze edildiği ve hedeflerin gelişimden, bir başka ifade ile, girdiden çok daha çok çıktı odaklı olduğu bir hedef belirleme şeklini öngörmüştür (Bach ve Sisson, 2001).

Performans yönetiminin, ikinci aşaması performans değerlendirmesidir (.Performans değerlendirmesi çalışan performansını belirtilen hedeflere ne ölçüde ulaşıldığını kontrol etmek için bir araçtır. Performans değerlendirmesi sürecinde temel olarak iki amaç vardır. $\mathrm{Bu}$ amaçlardan biri kontrol diğgeri ise gelişimdir (Harrison, 1997). Kontrol daha çok sert İKY olarak ele alınan tarafını temsil ederken diğer tarafta gelişim ise mülayim insan kaynakları yönetimi tarafını temsil etmektedir (Harrison, 1997).

Mülayim ve sert veya mekanik ve organik İKY uygulamalarını değerlendirecek olursak. Sert IKY uygulamalarında değerlendirme yukardan aşşağ işleyen, tek kaynaktan geri bildirim alınan, ve çıktılara dayanan bir süreçtir (Bach, 2002:260). İKY'nin sert tarafında performans değerlendirmesinde genelde nicel ölçütler kullanılmaktadır (Tamkin ve diğerleri, 2002). Burada temel amaç kişisel performans üzerinde kontrolü sağlamaktır (Bach, 2002).

Öbür tarafta ise, Mülayim İKY uygulamalarında ise performans değerlendirmesi, daha fazla kaynaktan geri bildirim alınan, gelişim odaklı değerlendirilenin katılımının olduğu ve çıktılardan çok girdilerin değerlendirildiği bir süreçtir (Bach, 2002:260). Performans yönetiminin yumuşak tarafında ise daha çok nitel ölçütler kullanılmaktadır (Tamkin ve diğerleri, 2002). Bir başka ifade ile sert İKY perspektifine göre değerlendirme çalışanın verimliliği ile ilgili bir değerlendirme iken öbür tarafta yumuşak İKY de değerlendirme çalışanın kendini ne ölçüde geliştirdiği ile ilgili bir süreçtir.

Performans yönetiminin son aşaması, performansın ödüllendirilmesi aşamasıdır. Ödül yönetiminin çalışanları örgütsel hedeflere motive etmek açain bir araç olarak kullanılmaktadır (Kessler, 2002). Mekanik İnsan Kaynakları Yönetimi uygulamalarında ödül sistemleri genelde bireysel performansı ödüllendirmeye yöneliktir (Nemetz ve Fry, 1988). Performansa dayalı ücret sistemi özellikle sert İKY uygulamalarının kullandığı temel yöntemdir amaç bireysel performansı, çıktılara dayanarak ödüllendirmektir (Kessler, 2002; Bach, 2002). Öbür tarafta ise, mülayim İKY uygulamalarında ödüllendirme daha çok yenilik odaklı ve grup çalışmasını motive eden ödül sistemleri kullanılmaktadır (Nemetz ve Fry, 1988; Bach, 2002). Performansa dayalı ücret sistemlerinde amaç çıtılara dayanan bir ödeme yaparak maliyet kontrolü 
sağlamaktır (Bach, 2002). Bir başka ifade ile temel odak kontroldür. Öbür tarafta ise yenilik odaklı ve takım odaklı ödüllendirme sisteminde de amaç yaratıcılığ 1 arttırmaktır (Nemetz ve Fry, 1988). Mekanik İKY uygulamalarında ödeme, ortalama seviyede iken, organik IKKY sistemlerinde ortalamnin üzerindedir (Bach, 2002).

\section{Strateji Tipolojileri ve Performans Yönetimi İlişkisi}

Örgütsel strateji ile insan kaynakları yönetimi arasındaki ilişkisi İKY uygulamalarınin hem strateji teorisyenleri (Bart, 1986) hemde stratejik İKY kuramciları tarafından kabul edilmiştir (Schuler ve Jackson, 1989). İKY uygulamalarının kapsamina giren yönetsel uygulamaları stratejiyi destekleyen, yönetsel davranışı uyandırdığ 1 için strateji araştırmacıları tarafından yapının (Bart, 1986) veya örgütsel dizaynın (Nemetz ve Fry, 1988) bir bileşeni olarak ele alınmıştır. $\mathrm{Bu}$ araştırmada da performans yönetimi örgüt dizaynını bir parçası olarak ele alınmaktadir.

Düşük maliyet liderliğinde, kararların merkeziliği esastır ve bilgi akışı dikey bir biçimde gerçekleşmektedir (Miller, 1988). Öbür tarafta ise farklılaşma stratejisinde kararların gayri merkeziliği, otonomi ve yetkenin dağıtılması ve yatay ve alttan üste iletişimin olması ve gücün pozisyondan kaynaklanması temel yapısal özelliklerdir ve örgütler kontrolü sağlamayı amaçlar (Miller, 1988). Farklilaşma stratejisinde kontrol düşükken; maliyet liderliğinde kontrol yüksektir (Nemetz ve Fry, 1988). Performans yönetiminin ise sert tarafı daha çok kontrol odaklı bir uygulama olarak adlandirlırken, mülayim tarafı gelişimsel ve katılımcı bir uygulama olarak nitelendirilmiştir (Bach, 2002). Düşük maliyet liderliği benimseyen bir firma örgütsel dizayna kontrol odaklı sert performans yönetimi uygulamalarını entegre ederken, öbür tarafta farklılaşma stratejisi uygulayan firma yenilik için daha katılımcı performans yönetimi uygulamalarını entegre edecektir. Kontrol, yenilik ve ya- ratıcılık negatif ilişkili kavramlardır (Miller, 1988). Buradan hareketle:

Önerme 1 Maliyet liderliği stratejisi uygulayan firmalar sert performans yönetimi uygulamalarını kullanırken öbür tarafta farklılaşma stratejisi olan firmalar mülayim performans yönetimi süreçlerini uygulayacaklardir.

Performans yönetiminin ilk aşaması olan hedef belirlemede ise performans yönetiminin mülayim tarafı hedeflerin belirlenmesi sürecinde çalışanların katılımının motivasyonu arttıracağını tartışmış ve hedef belirleme sürecinde çalışanların katılımının çok önemli olduğunu tartışmıştır (Bach, 2002). Performans yönetiminin sert taraf1, hedeflerin yukarıdan aşşağ 1 şekilde belirlenmesini öngörmüștür (Bach, 2002). Kararların merkeziliğini ve yetkenin hiyerarşiye bağlanmasını gerektiren düşük maliyet liderliği stratejisinde (Miller, 1986) hedeflerin belirlenmesi yukarıdan aşşağı empoze edilmesi şeklinde olacacaktır. Öbür tarafta ise otonominin, katılımin fazla olduğu ve merkezileşmenin düşük olduğu farklılaşma stratejisinde (Miller, 1988;1986) örgütlerin hedef belirleme sürecinde katılımı daha çok öne çıkaracakları tartışılabilmektedir. Buradan hareketle:

Önerme 2: Düşük maliyet liderliği stratejisine sahip örgütlerde hedef belirleme sürecinde katılım düşük olacaktır.

Önerme 3: Farkl1laşma stratejisine sahip örgütlerde tam tersi olarak hedef belirleme sürecinde katılım daha yüksek olacaktır.

Performans yönetimi sürecinin ikinci aşaması performansın değerlendirilmesi aşamasidır (Bach, 2002). Bir tarafta sert İKY de performans değerlendirmesi yukarından aşşağı işleyen, çıktı odaklı, nicel ölçütlerin kullanıldı̆̆ 1 bir süreçtir (Harrison, 1997). Öbür tarafta ise tam tersi olarak mülayim performans yönetimi uygulamalarında ise, performans değerlendirmesi, girdilerin bir başka ifade ile gelişimin değerlendirildiği, daha çok nitel ölçütlerin kullanıldığ 1 ve değerlendirmenin hem dikey hem yatay bir şekilde 
işlediği bir süreçtir (Harrison, 1997).

Maliyet liderliğinde temel hedef bütçe kontrolü ve maliyet minimizasyonu olduğu için (Miller, 1986; 1988) değerlendirme sürecinde maliyet perspektifinden bakilacak ve daha çok çıktılar üzerinde yoğunlaşacaktır ve bütçe kontrolü gereksiniminde dolayıda değerlendirme nicel ölçütler üzerinden olacaktır. Yetkinlikler üzerinden değerlendirmek yetkinlik odaklı eğitim ve gelişim politikası gerektireceğinden ve eğitim ve gelişim üzerine daha fazla yatırım gerektireceğinden (Lado ve Wilson, 1994) bu da maliyetleri arttıracağ 1 için maliyet liderliğ $i$ stratejisinde önemli bir araç olmayacaktır. Öbür tarafta ise farklılaşma stratejisinde, temel amaç yaratıcılık ve yenilik olduğu için (Miller; 1986; Nemetz ve Fry, 1988) yetkinlik gelişimi ve bilgi ve yetenek yoğunluğunun artması da yaratıcılığı geliştireceği için (Lado ve Wilson, 1994) farklilaşma stratejisinde değerlendirme yetkinlik ve gelişim odaklı olacaktır. Yine yetkinlik odaklı değerlendirme ile uyumlu bir şekilde değerlendirmede nitel kriterler kullanilacaktır.

Maliyet liderliği stratejisi izleyen örgütlerde kararların merkezi olması, otoritenin merkeziliği ve dikey iletişim (Miller; 1986; 1988) değerlendirme sürecinde tek kaynaktan üstün astı değerlendirmesi şeklinde bir yaklaşım gerektirecektir. Öbür tarafta, daha gayri-merkeziyeti, yatay ve alltan üste kat1lımcı iletişimi teşvik eden (Nemetz ve Fry, 1988) farklılaşma stratejisinde ise daha çok kaynaklı bir değerlendirme mekanizmasının olacağı tartışılabilir. Bu varsayımlardan hareketle:

Önerme 4 Maliyet liderliği stratejisi izleyen örgütlerde, sert performans yönetimi uygulamaları söz konusu olacağı için, performans değerlendirmesi, çıtı odaklı, nicel ve tek kaynaklı olacaktır.

Önerme 5 Farklılaşma stratejisi izleyen örgütlerde, mülayim performans yönetimi söz konusu olacağ 1 için, performans değerlendirmesi girdi odaklı, nitel ve çok kaynaklı olacaktır.
Performans yönetiminin son aşaması değerlendirilen performansın ödüllendirilmesidir (Harrison, 1997). Bir başka ifade ile, ücretin performansa bağlanmasıdır (Bach, 2002). Bir tarafta sert insan kaynakları yönetiminde ücret seviyesi ortalama seviyede belirlenip ücret performans değerlendirmesine bağlanırken, mülayim iky uygulamalarında yetkinliği daha yüksek çalışanların örgüte kazandırılması için ücret seviyesi averajın üstünde tespit edilmekte ve ödüllerde yeniliği ve takım çalışmasını özendirici, takım odaklı ödeme veya bonuslar şeklinde olmaktadir (Armstrong ve Murlis, 1998). Düşük maliyet stratejisini değerlendirdiğimizde amaç verimlilik, maliyet kontrolü ve maliyetleri düşürmektir (Bart, 1986). Bu sebeple de averaj bir ücret seviyesi ve ödülü performansa dayandırmak maliyetin düşürülmesi ve kontrol edilmesi açısından gerekli olacaktır. Averaj ücret seviyesi maliyet düşüşü sağlayacak, performansa dayalı ücret ise maliyet kontrolü sağlayacaktır.

Maliyet liderliği stratejisinde, maliyeti düşürmek için kitlesel üretim gereklidir (Nemetz ve Fry, 1988). Kitlesel üretim ise işin (Miller, 1988) ve çalışan davranışlarının (Mintzberg, 1979) standardizasyonunu ve formalizasyonunu gerektirir. Çünkü formalizasyon çalışan davranışlarının değikenliğini azaltır ve tahmin ve kontrol edilmesini kolaylaştırır. Öbür tarafta ise ücrete dayalı bir performans değerlendirme sisteminin örgütlerde kabul edilen davranış için çerçeve çizdiği ve kontrol sağladığ 1 tartışılmıştır (Hendry ve diğerleri, 2000). Bu sebeple davranış formalizasyonu sağlamak açısından, maliyet liderliği stratejisinde performansa dayalı ücret sistemi kullanılacaktır.

Öbür tarafta, farklılaşma stratejisinde ise ana amaç yenilik olduğu için yenilikte yaratıcılık gerektirdiği için standardizasyonun yerini esneklik alacaktır (Miller, 1998). Farklılaşma stratejisi uygulayan bir firma daha fazla oranda teknokrat çalıştıracaktır ayrıca bu stratejini için yatay iletişim gereklidir. (Miller, 1988). Bu sebeple yeniliği özendiren yenilik odaklı ve yatay iletişimi destekleyen 
grup odaklı ödül sistemleri daha uyumlu olacaktır. Ayrıca Randle (1997) ilaç sektöründe Pharmex adlı firmada ar-ge çalışanları üzerinde yaptığı araştırmada, performansa dayalı ücretin bilim adamları tarafindan sevilmeyen bir uygulama olduğu ve çoğu zaman subjektiflik problemlerinden dolayı da anti-motivatör olduğu da bulgulanmıştır. Bu varsayımlardan hareketle:

Önerme 6 Maliyet liderliği stratejisi uygulayan örgütlerde, sert performans yönetimi uygulamaları kullanılacağı için ödüllendirmede performansa dayalı ücret sistemi kullanılacaktır.

Önerme 7 Farklılaşma stratejisi uygulayan örgütlerde, mülayim performans yönetimi uygulamaları kullanılacağı için ödüllendirme takım ve yenilik odaklı ödüllendirme olacaktır.

\section{Sonuç}

Şimdiye kadarki araştırmalar işletme stratejisi ile genel insan kaynakları yönetimi ve ödül, eğitim ve ișe alım gibi bir takım alt alanları ile ilişki kurulmuştur (Schuler ve Jackson, 1989; Olian ve Rynes, 1994; Raghuram, 1994; Raghuram ve Arvey, 1994). Bu araştırmada daha önce insan kaynakları yazınında ele alınmayan performans yönetimi ile işletme stratejisinin ilişkisi ele alınıp incelenmiştir. Bu ilişki ele alınırken, strateji Porter'ın(1980) düşük maliyet liderliği ve farklılaşma olmak üzere iki temel işletme seviyesindeki jenerik stratejiler yönü ile ele alınmıștır. Performans yönetimi, ise hedef kurma, değerlendirme ve ödüllendirme olmak üzere üç aşamada ele alınıp incelenmiştir. Araştırmada işletme stratejisi ile performans yönetimi arasındaki ilişki koşulbağımlılıksal, belirlenimci perspektif, ile alınmış ve bir takım stratejilerin bir takım yapısal uygulamalar ortaya çıkaracağı öne sürülmüştür.

Araştırmada varolan kuramsal yazın 1ş1ğında, örgütlerin izledikleri stratejilere göre performans yönetimi uygulamalarının nasıl farklılaşacağına ilişkin öneriler ortaya koyulmuştur. Araştırma sonucu olarak, mali- yet liderliği stratejisinde örgütsel dizaynın parçası olarak sert performans yönetimi uygulamalarının öne çıkacağı, öbür tarafta ise farklılaşma stratejisi izleyen firmalarda ise mülayim performans yönetimi uygulamalarının kullanılacağı tartışılmıştır.

Araştırmanın, uygulamaya dönük sonucu ise farklı stratejiler için bir takım performans yönetimi uygulamaları ve bunların uyumluluğunu tartışarak uygulayıcıları ne tür stratejiler ile ne tür uygulamaların bağdaşabileceği konusunda bir çerçeve çizmiştir.

Stratejik yönetim ile insan kaynakları yönetimi ilişkisi kuramsal olarak (Jackson ve Schuler, 1987; Miles ve Snow, 1984) kurulmuş iken şu ana kadar ampirik olarak geçerlenmiş çok az araştırma vardır .(Balkin ve Gomez-Meja, 1990; MacDuffee ve Kochan, 1995)Bu sebeple bundan sonra yapılacak çalışmaların bu kurulan ilişkilerin ampirik testine yönelik olmalıdır. 


\section{Kaynakça}

Armstrong, M. \& Murlis, H. 1998. Reward Management: A Handbook of Remuneration Strategy and Practice. London: KOGAN PAGE

Bach,S. 2002. "From Performance Appraisal to Performance Management" in Bach, S. \& Sisson, K. (Ed), Personnel Management: A Comprehensive Guide to Theory and Practice. Oxford, Blackwell, pp: 241-264.

Balkin, D.B. ve G'omez-Meja, L.R. 1990. Matching Compensation and Organisational Strategies, Strategic ManageMent Journal, 11: 153-69.

Barney, J. 1991. Firm Resources and Sustained Competitive Advantage, Journal of Management, 17: 99-120.

Bart,C,K.1986. Product strategy and formal structure. Strategic Management Journal. 7,293-312.

Boxall, P. ve Steeneveld, M. 1999. Human Resource Strategy and Competitive Advantage: A Longitudinal Study of Engineering Consultancies. Journal of Management Studies, 36:4, 443-463.

Delery, J.E. and Doty, D.H. 1996. Modes of Theorising in strategic Human Resource Management: Tests of Universalistic, Contingency and Configurational Performance Predictions, The Academy of Management Journal, 39:4, 802-835.

Dess,G,G., ve Davis,P,S. 1984. Porter's (1980) generic strategies as determinants of strategic group membership and organizational performance. The Academy of Management Journal. 27, 467-488.

Galbraith,C., ve Schendel,D.1983. An empirical analysis of strategy types. Strategic Management Journal. 4, 153-173.
Guest, D. \& Conway, N. 2001. Organisational Change and the Psychological Contract: CIPD Research Report. London: CIPD.

Guest, D. ve Conway, N. 1998. Fairness at Work and the Psychological Contract: the fourth annual IPD survey of the state of the employment relationship. London: IPD.

Harrison, R. 1993. Human Resource Management: Issues and Strategies. Cambridge: Addison-Wesley Publishers.

Hendry, C., Woodward, S., Bradley, P., Perkins, S. 2000. Performance and rewards: cleaning out the stables. Human Resource Management Journal, 10:3, 46-62.

Huselid, M,A.,Jackson, S,E. ,Schuler, R,S. 1997. Technical and strategic human resource management effectiveness as determinants of firm performance. The Academy of Management Journal. 40:1,171-188.

Kessler, I. 2002. "Remuneration Systems" in Bach, S. \& Sisson, K. (Ed), Personnel Management: A comprehensive guide to Theory and Practice, Oxford, Blackwell: s. 264-287.

Lado,A,O. ve Wilson,M,C.1994.Human resource systems and sustained competitive advantage: A competency based perspective. The Academy of Management Review, 19,699-727.

Legge, K. 1995. Human Resource Management: Rhetorics and Realities. London: MACMILLAN PRESS.

Miles, R. and Snow, C.H. 1984. Designing Strategic Human Resource Systems, Organizational Dynamics, 36-52.

Miller,D.1986.Configurations of strategy and structure. Strategic Management Journal, 7,233-249. 
Miller,D.1988.Relating Porter's strategy to environment and structure. The Academy of Management Journal. 31,280308.

Miller,D.1996. Configurations revisited. Strategic Management Journal. 17, 505-512.

Mintzberg.H. 1979. The Structuring of Organizations.NJ.Prentice Hall.

Nemetz,P,L, ve Fry,L,W. 1988. Flexible manufacturing organizations: Implications for strategy formulation and organization design. The Academy of Management Review. 13,627-638.

Raghuram, S. 1994 'Linking Staf. ng and Training Practices with Business Strategy: A Theoretical Perspective', Human Resource Development Quarterly, 5(3): 23751.

Raghuram, S. and Arvey, R.D. 1994. Business Strategy Links with Staf. ng and Training Practices., Human Resource Planning, 17(3): 55-73.

Randle, K .1996. Rewarding failure: operating a performance-related pay system in pharmaceutical research. Personnel Review, 26:3, 187-200.

Sanz-Valle,R.,Sabater-Sachez,R.,AragonSanchez,A. 1999. Human resource management and business strategy links: An empirical study. The International Journal of Human Resource Management. 10,655-671.

Schuler, R. and Jackson, S. 1987. Linking competitive strategies with human resource management practices, The Academy of Management Executive, 1(3): 207-19.

Schuler,R., ve Jackson,S,E. 1989. Determinants of human resource management priorities and implications for industrial relations. Journal of Management. 15,8999.
Snow, C.C. and Hambrick, D.L. 1980. Measuring organizational strategies: some theoretical and methodological problems, Academy of Management Review, 5, 527-38.

Wright,P,M. ve Snell,S,A.1998.Toward a unifying framework for exploring fit and flexibility in strategic human resource management.The Academy of Management Journal, 23:4,756-772. 